\title{
A Pegada Ecológica como instrumento de educação ambiental: o estudo de caso da cidade de Campina Grande-PB
}

The Ecological Footprint as an environmental education tool: the case study of the city of Campina Grande-PB

\section{La Huella Ecológica como instrumento de educación ambiental: el caso de estúdio de la ciudad de Campina Grande-PB}

\section{Resumo}

A Educação Ambiental formal é o canal mais eficaz para desenvolver no indivíduo a cidadania e a reflexão contínua do papel que o mesmo exerce na sociedade. A Pegada Ecológica pode ser definida como uma medida de sustentabilidade, no âmbito se quantificar os recursos naturais e fornecer dados para a análise da capacidade de suporte da terra. Nesse contexto, a presente pesquisa teve por objetivo, avaliar a percepção da população sobre a pegada ecológica no município de Campina Grande-Paraíba. A técnica utilizada na pesquisa foi documental, bibliográfica, com caráter qualitativo e quantitativo. Foi coletado dados do Censo escolar 2021 e aplicado questionário com 10 (dez) questões objetivas para um grupo de 47 pessoas. Como resultados, obteve-se que a Pegada Ecológica contribui efetivamente para o reconhecido dos problemas ambientais, mas ainda está aquém do conhecimento de muitos dos respondentes. Ainda se constatou que mesmo a escola sendo o maior aglutinador de pluralidade de conhecimentos, muito há de se fazer unindo o meio-ambiente à educação.

Palavras-chave: Meio Ambiente; Sustentabilidade; Educação ambiental.

\begin{abstract}
Formal Environmental Education is the most effective channel for developing citizenship in the individual and the continuous reflection on the role that he/she plays in society. The Ecological Footprint can be defined as a measure of sustainability, within the scope of quantifying natural resources and providing data for the analysis of the carrying capacity of the land. In this context, this research aimed to evaluate the population's perception of the ecological footprint in the city of Campina Grande-Paraíba. The technique used in the research was documentary, bibliographical, with a qualitative and quantitative character. Data from the 2021 School Census were collected and a questionnaire with 10 (ten) objective questions was applied to a group of 47 people. As a result, it was found that the Ecological Footprint effectively contributes to the recognition of environmental problems, but it is still beyond the knowledge of many of the respondents. It was also found that, even though the school is the greatest aggregator of plurality of knowledge, there is still a lot to be done by uniting the environment with education.
\end{abstract}

Keywords: Environment; Sustainability; Environmental education.

\section{Resumen}

La Educación Ambiental Formal es el canal más eficaz para el desarrollo de la ciudadanía en el individuo y la reflexión continua sobre el papel que desempeña en la sociedad. La Huella Ecológica se puede definir como una medida de sostenibilidad, dentro del alcance de cuantificar los recursos naturales y proporcionar datos para el análisis de la capacidad de carga de la tierra. En este contexto, esta investigación tuvo como objetivo evaluar la percepción de la población sobre la huella ecológica en la ciudad de Campina Grande-Paraíba. La técnica utilizada en la investigación fue documental, bibliográfica, de carácter cualitativo y cuantitativo. Se recogieron datos del Censo Escolar 2021 y se aplicó un cuestionario con 10 (diez) preguntas objetivas a un grupo de 47 personas. Como resultado, se encontró que la Huella Ecológica contribuye efectivamente al reconocimiento de los problemas ambientales, pero aún está más allá del conocimiento de muchos de los encuestados. También se constató que, si bien 
la escuela es la mayor pluralidad aglutinante de saberes, aún queda mucho por hacer vinculando el medio ambiente con la educación.

Palabras clave: Medio ambiente; Sustentabilidad; Educación ambiental.

\section{Introdução}

Para a sociedade atual atingir os objetivos do desenvolvimento sustentável (ODS), de acordo com a Agenda 2030, é necessário que ocorra alterações de hábitos, principalmente relativa ao modus operandi do consumo e da produção, que são dois aspectos importantes para se obter a diminuição da pegada ecológica em relação ao ponto de vista ambiental.

De acordo com PNUD (2021), o gerenciamento proveitoso dos bens e serviços ecossistêmicos ambiental, assim como o manejo adequado dos resíduos e poluentes, são temas relevantes para conseguir ter êxito nos ODS, e a pegada ecológica está relacionada com os ODS 12, consumo e produção sustentável, incentivando o uso de energia e recursos naturais de maneira eficiente, disponibilidade aos serviços básicos e sustentabilidade na infraestrutura.

A Pegada Ecológica (PE) é reconhecida como uma medida de sustentabilidade porque pode quantificar o consumo de recursos naturais e fornecer dados para a análise da capacidade de suporte da terra. Pode calcular o tamanho da área de produção usada para produzir os recursos necessários para apoiar o estilo de vida de indivíduos, cidades, regiões ou países (REES, 1992).

Iazdi e Pedroso (2020) afirmam que a PE é fundamental para estimar o consumo dos recursos naturais, servindo como base para o planejamento de políticas voltadas a sustentabilidade, por ser considerado um indicador e que possibilita uma compreensão acessível, bem como pode ser aplicada como uma ferramenta que proporciona averiguar a proporção do uso da terra e visualizar diferentes situações relacionados ao uso dos recursos naturais e suas potencialidades.

Um dos caminhos para amenizar os problemas ambientais é a conscientização da população através da pegada ecológica inserida na Educação Ambiental formal e principalmente não-formal com o intuito de desenvolver o cidadão como um ser crítico, ativo e reflexivo para que o mesmo possa dar continuidade levando esse conhecimento para a sociedade.

Cardoso et al (2021) relatam que essa base é necessária para que se possa entender a importância da educação não formal no ambiente não escolar e contribuir para a conscientização pessoal sobre o meio ambiente de forma a transformar pessoas que possam explicar os problemas ambientais que ocorrem no ambiente escolar. Seu entorno, indivíduos que podem tomar decisões com base na realidade do ambiente em que vivem

A educação ambiental escolar e o ensino sobre a Pegada Ecológica auxiliam na formação de cidadãos responsáveis, preparados para assumir seus papéis socioambientais e contribuírem para o seu bem-estar visando as futuras gerações. No âmbito escolar, a Educação Ambiental é essencial para a percepção ambiental para a formação dos discentes, como relatam Santos e Gardolinski (2020).

O estudo da pegada ecológica é uma ferramenta que ameniza os problemas ambientais hodiernos, e promove a sustentabilidade, passando a ter noção altruísta do consumo excessivo e a realidade ambiental. Galli et al. (2020) afirmam que a PE pode ser uma maneira de expor os danos ambientais resultantes da exploração dos recursos naturais para suprir a demanda do consumismo. Santos et al. (2021) descrevem que a PE é uma metodologia aplicável para desenvolvimento da educação ambiental, explicitando sobre o modo de vida dos estudantes e seus possíveis danos ambientais, ampliando as discussões e permitindo o entendimento dos discentes sobre suas ações não sustentáveis e seus efeitos ao meio ambiente.

Nesse contexto, a presente pesquisa foi realizada objetivando-se avaliar a percepção da população sobre a pegada ecológica. 


\section{Metodologia}

A pesquisa é um estudo de caso com caráter qualitativo e quantitativo, com análise documental e bibliográfica, cujos dados foram construídos através da aplicação de questionário próprio aplicado como instrumentos de coleta de dados, com foco em avaliar o conhecimento ambiental de um grupo de pessoas anônimas voltado à Pegada Ecológica. Assim, como foram coletados dados do Censo Escolar de 2021, INPE (2021), sobre o estado da Paraíba e do município de Campina Grande-PB.

De acordo com Pereira et al. (2018), na abordagem qualitativa a compreensão do pesquisador é fundamental para analisar a situação, na qual o questionário é uma das maneiras de se obter as informações. Em relação a abordagem quantitativa, esses autores relatam que a coleta de informações numéricas resulta em dados para poderem ser analisados. Os estudos de casos retratam grupos específicos no qual concentra-se a pesquisa, como descrevem Severino (2017) e Pereira et al. (2018).

O estudo de caso foi realizado na cidade de Campina Grande, estado da Paraiba, a $120 \mathrm{Km}$ da capital João Pessoa, com uma população de mais de 400 mil habitantes (IBGE, 2020). Sobre os aspectos econômicos, o Produto Interno Bruto, PIB per capita, teve valor superior a 21 mil reais (IBGE, 2017).

Figura 1. Localização do município de Campina Grande-PB.

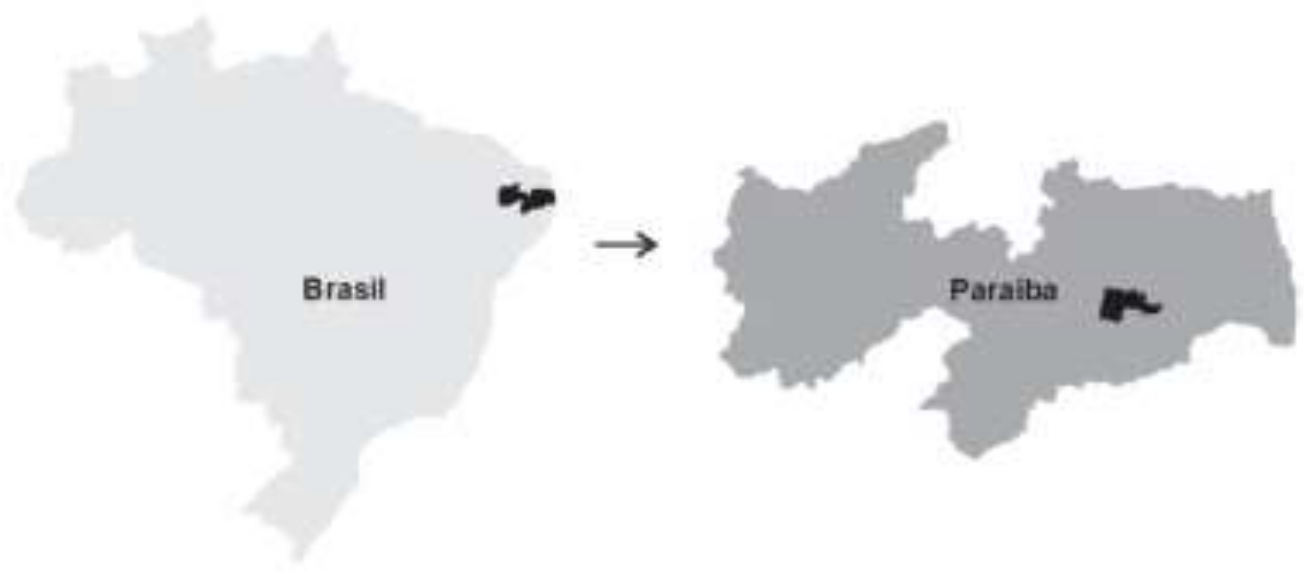

Fonte: Silva (2021).

O estudo de caso foi realizado objetivando-se avaliar o conhecimento ambiental de um grupo de pessoas voltado à Pegada Ecológica, buscando responder a seguinte questão: Qual a percepção ambiental das pessoas referente a pegada ecológica?

O questionário conteve 10 (dez) questões objetivas que as respostas variam entre Sim e Não, Sabia ou Não e Finitos ou Infinitos, foi aplicado para um grupo de 47 pessoas a fim de avaliar o conhecimento entre meio ambiente, recursos naturais e Pegada Ecológica, utilizando o recurso digital Google Forms. Na aplicação dos questionários os participantes não foram identificados.

Para atingir este objetivo, os seguintes objetivos específicos foram abordados: Identificar a partir das teorias e estudos a importância da PE (Pegada Ecológica) no contexto social; Identificar o conhecimento das pessoas pesquisadas com relação à Pegada Ecológica e meio ambiente; Compreender as dificuldades da relação entre pegada ecológica e sociedade. 


\section{Resultados e Discussão}

No estado da Paraíba, observa-se na Figura 2, que a maioria dos alunos matriculados no Ensino Fundamental, está no ensino parcial, ou seja, estudam em apenas um horário (turno), resultado semelhante é constatado no município de Campina Grande -PB. Nota-se que a quantidade de alunos matriculados no Ano inicial parcial em Campina Grande (CG) representa quase $11 \%$ de toda a Paraíba (PB), enquanto o integral é de 2,3\%. Já para os alunos matriculados nos anos finais parciais em CG averígua-se uma porcentagem de aproximadamente $10 \%$ e para o integral de $13,15 \%$ do total de alunos nessas séries na PB.

Figura 2. Alunos matriculados no Ensino Fundamental no ano de 2021 em Campina Grande-PB.

\section{Ensino Fundamental}

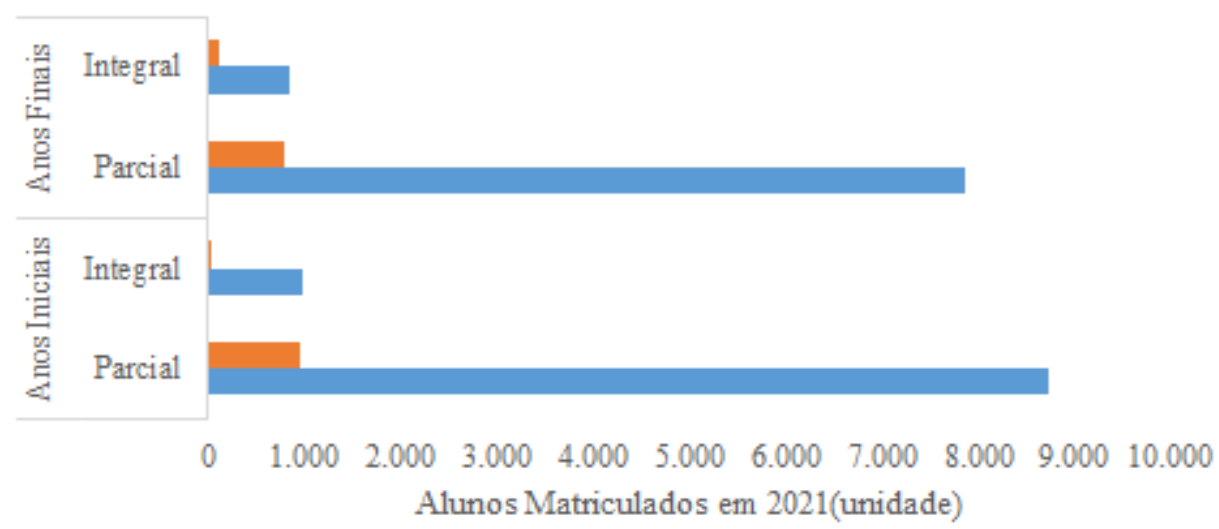

-CAMPINAGRANDE -PARAIBA

Fonte: Autores (2021).

Os alunos matriculados no Ensino Médio no estado da Paraíba para o ano de 2021 foram de 1060 alunos para um turno e de 1355 alunos para o ensino médio integral, observando que houve aumento de $27,8 \%$ no ensino integral em relação ao parcial, Figura 3. O ensino médio parcial e integral de CG corresponde a 17,26\% e 8,85\%, respectivamente em relação ao total de alunos matriculados nessas séries na Paraíba. 
Figura 3. Alunos matriculados no Ensino Médio no ano de 2021 em Campina Grande-PB.

\section{Ensino Médio}

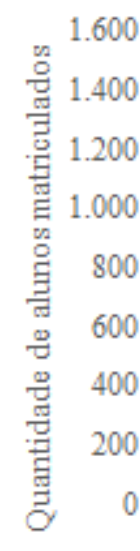

$$
\begin{aligned}
& 600 \\
& 400 \\
& 200 \\
& 000 \\
& 800 \\
& 600 \\
& 400 \\
& 200
\end{aligned}
$$

- Médio Parcial = Médio Integral

Fonte: Autores (2021).

No Ensino de Jovens e Adultos na Paraíba, Figura 4, nota-se que mais de 2 mil alunos são do ensino fundamental e cerca de 500 alunos para o nível médio, Figura 4. No município de Campina Grande 130 alunos estão matriculados no ensino fundamental EJA e quase 100 no ensino médio.

Figura 4. Alunos matriculados no Ensino de Jovens e Adultos (EJA) no ano de 2021 em Campina Grande-PB.

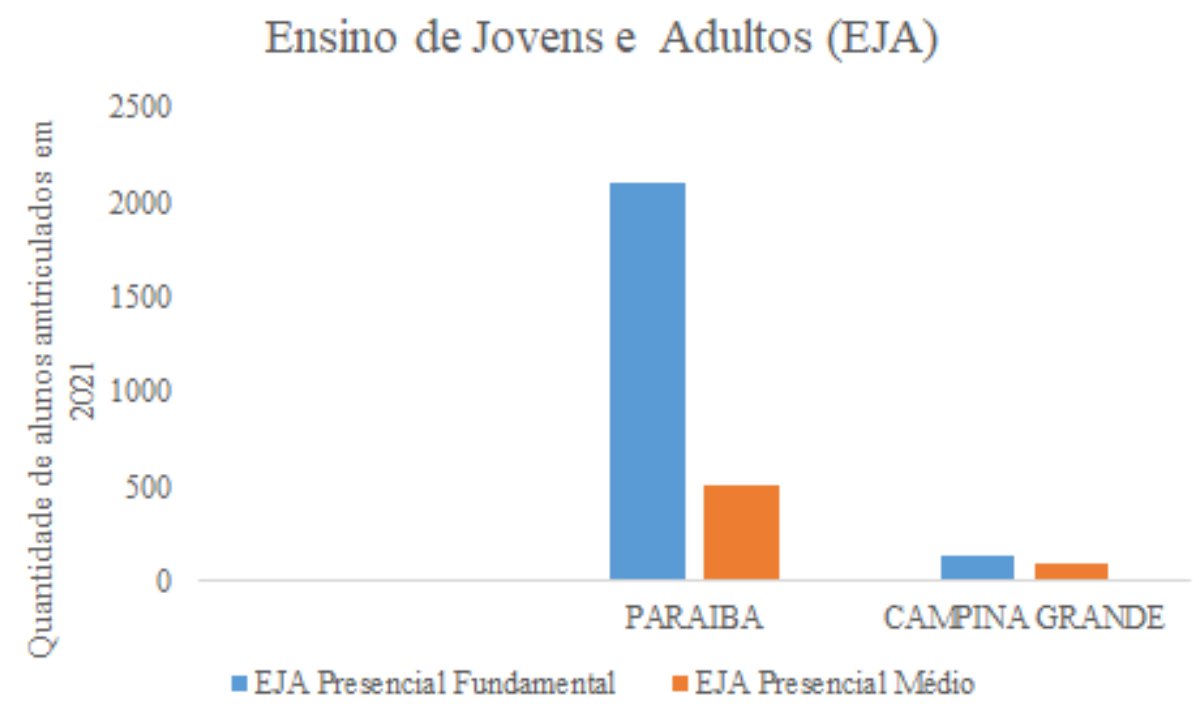

Fonte: Autores (2021).

Araújo et al. (2020) ao analisarem a percepção ambiental de estudantes do ensino fundamental de uma escola pública no município de Campina Grande-PB, observaram que os alunos descrevem o meio ambiente sem a inclusão do ser humano, relatando sua forma natural, sendo notório uma percepção preservacionista, havendo diferenças significativas sobre meio ambiente e percepção ambiental, sendo necessário a aplicação da Educação Ambiental, ficando evidente que não há profundidade nos conteúdos sobre meio ambiente, sendo abordado temas superficiais. 
O ensino da Educação Ambiental, segundo Viana et al. (2019) devem ser iniciados nos anos iniciais da escolaridade, por ser nessa fase que a personalidade está em formação da cidadania da criança.

Na Figura 5, nota-se que 100\% das pessoas abordadas já ouviram falar sobre o meio ambiente e consideraram importante a preservação de ecossistemas naturais, $95 \%$ se interessam por assuntos ligados ao meio ambiente e 4,3\% não possui o interesse ao tema. $97 \%$ conhece o meio ambiente enquanto que $2,1 \%$ não.

Quanto à pergunta sobre Pegada Ecológica, 38,3\% responderam que desconhecem e 61,7\% conhecem sobre a pegada ecológica. Assim como 97,9\% das pessoas pesquisadas sabem o que são recursos naturais, enquanto 2,1\% responderam que não sabem, Figura 5, destacando a importância da conscientização da população através da educação ambiental.

Figura 5. Análise da percepção dos participantes sobre pegada ecológica obtidas pelos questionários semiestruturados aplicados em Campina Grande-PB.

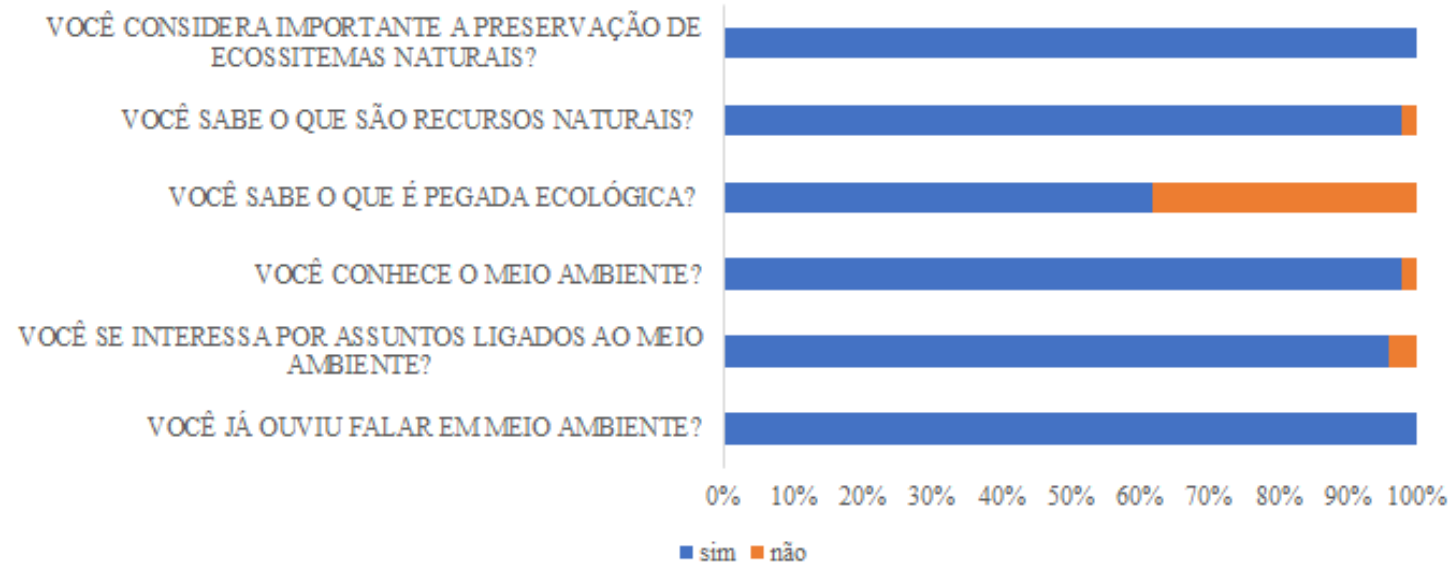

Fonte: Autores (2021).

A escola é o local ideal para aplicar a Educação Ambiental, segundo Souza (2020) o ambiente escolar se destaca como centro de atividades e relacionamentos, devendo estimular a libertação do consumismo e do capitalismo. Santos \& Silva (2021) afirmam que é no ambiente formal e não formal que o escopo da educação ambiental continua se expandindo.

Aplicando a pegada ecológica como metodologia para educação ambiental, Santos et al. (2021) observaram que antes de aplicar esta intervenção, constataram que apenas $19 \%$ dos alunos conheciam sobre a pegada ecológica, enquanto $81 \%$ não conhecia este termo, resultados superiores foram obtidos nessa pesquisa.

Resultados divergentes foram obtidos por Berté (2019) ao aplicar um questionário numa escola rural e urbana, em uma turma de $8^{\circ}$ ano, constataram que os alunos participaram de algum projeto voltado ao Meio Ambiente, contudo cerca de $75 \%$ não sabiam explicar o que era a Pegada Ecológica.

Quando os participantes da pesquisa foram indagados sobre: "A Pegada Ecológica de um país, de uma cidade ou de uma pessoa, corresponde ao tamanho das áreas produtivas de terra e de mar, necessárias para gerar produtos, bens e serviços que sustentam seus estilos de vida. Em outras palavras, trata-se de traduzir, em hectares (ha), a extensão de território que uma pessoa ou toda uma sociedade "utiliza", em média, para se sustentar. (WWF BRASIL, 2007.p. 2)." Aproximadamente 60\% dessas pessoas sabiam que a pegada ecológica é medida por hectares de acordo com seu consumo e 40,4\% não sabiam. 
Figura 6. Análise das respostas obtidas pelos questionários semiestruturados aplicados em Campina Grande-PB.

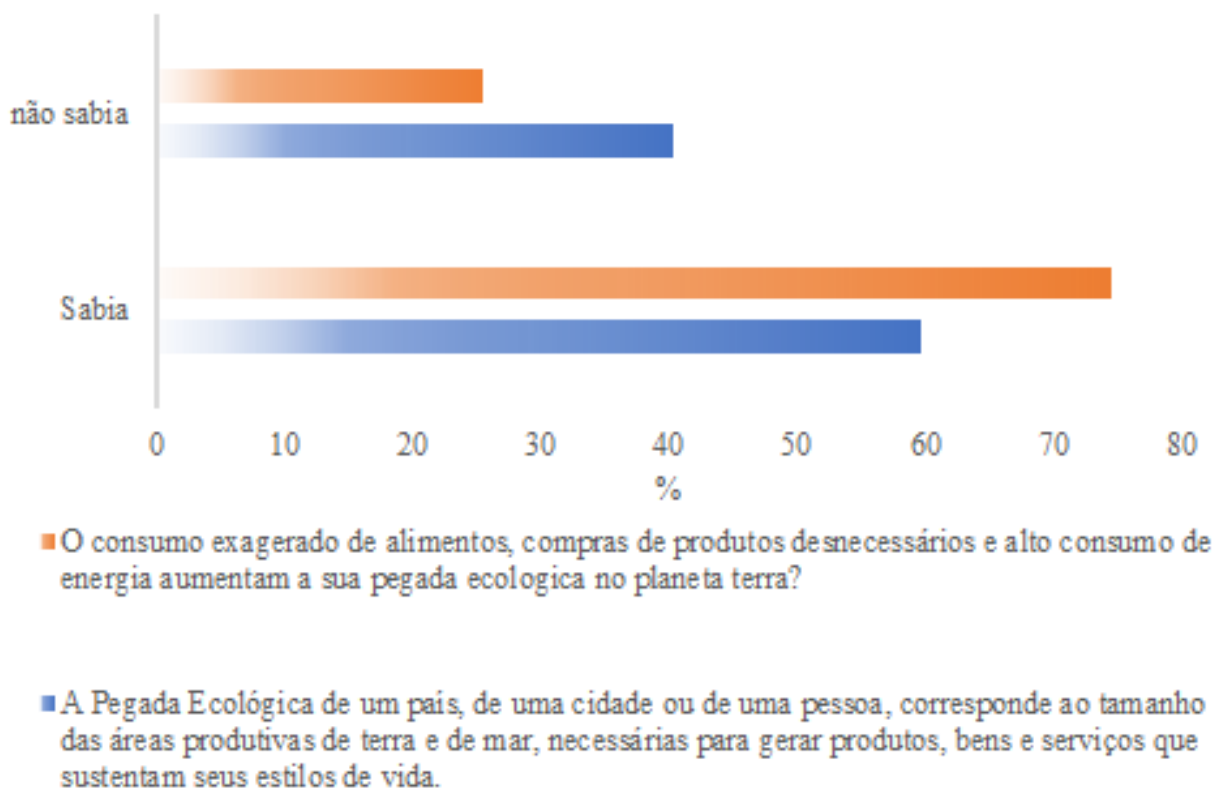

Fonte: Autores (2021).

De acordo com a Figura 6, o consumo exagerado, 74,5\% sabiam que esse hábito aumenta a pegada ecológica, enquanto que $25,5 \%$ não sabiam. Apesar de saberem que isso pode implicar em aumento da PE, as pessoas continuam com seu hábito consumista, o que vem apenas afirmando que existe um déficit na conscientização ambiental.

A Pegada Ecológica, segundo Schwambach (2013), podem ser influenciadas de acordo com os padrões de consumo empregados por cada pessoa em seu cotidiano, podendo aumentar ou diminuir, o que pode reduzir este índice é evitar produtos que contenham embalagem, como enlatados, e incluir na sua vida a reciclagem, são algumas das atitudes que contribuem na diminuição da pegada ecológica individual.

Os participantes ao responderem a pergunta se o ambiente atual pode ser considerado sustentável, cerca de $74,5 \%$ responderam que o ambiente não está sustentável da forma em que se encontra, mas, 25,5\% discordaram. 
Figura 7. Análise das respostas obtidas pelos questionários semiestruturados aplicados em Campina Grande-PB.

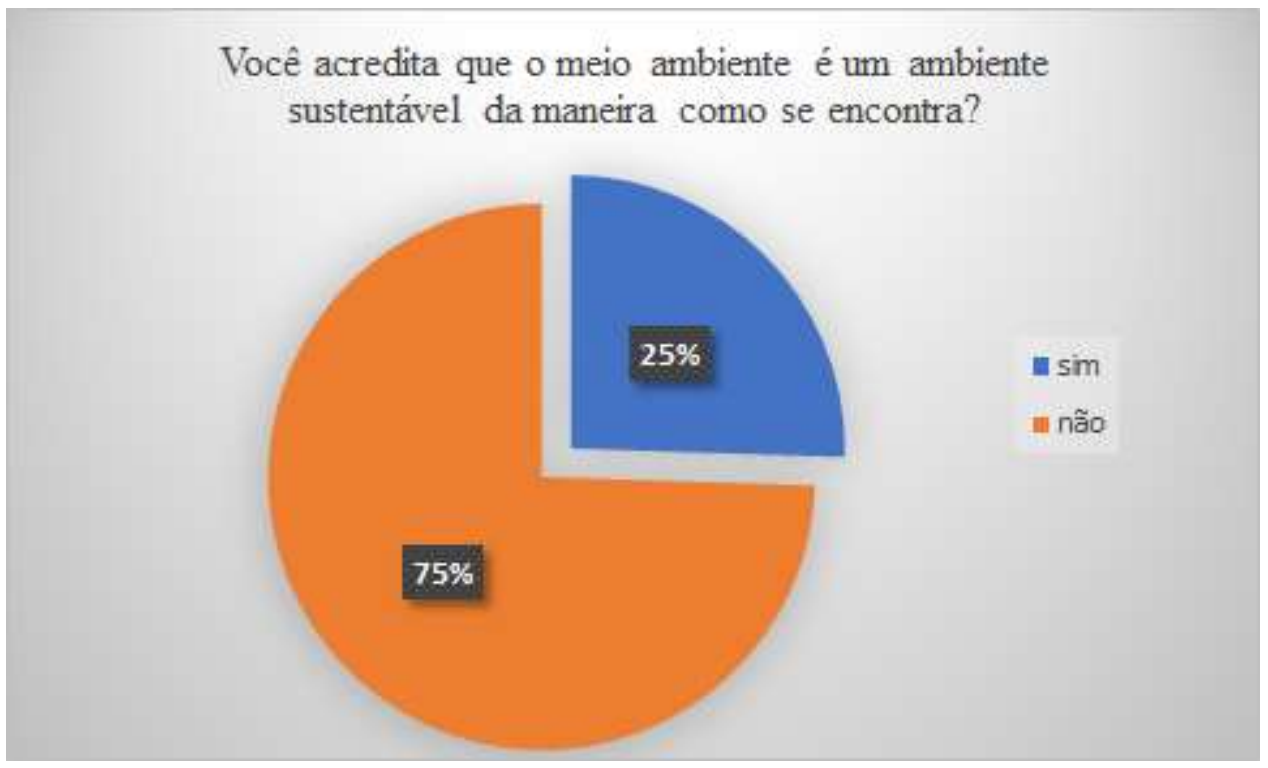

Fonte: Autores (2021).

Esse tipo de resposta, corrobora com o pensamento de Rodrigues et al. (2019) os quais relatam que ao longo dos anos, a maneira como os humanos usam a natureza para atender às suas necessidades trouxe direta ou indiretamente uma série de consequências catastróficas para a natureza e para os próprios humanos, e a ausência de medidas sustentáveis efetivas vem apenas potencializando a degradação ambiental.

$\mathrm{Na}$ questão sobre se os recursos naturais são finitos ou infinitos, Figura 8, verifica-se que 70,2\% responderam que os recursos naturais são finitos, porém, 29,8\% afirmam que são infinitos. Dessa maneira, percebe-se que os participantes têm noção que os recursos naturais são esgotáveis, mas precisam se conscientizar que a maneira que está sendo consumida, de forma insustentável, não irá durar por muito tempo.

Figura 8. Análise das respostas obtidas pelos questionários semiestruturados aplicados em Campina Grande-PB.

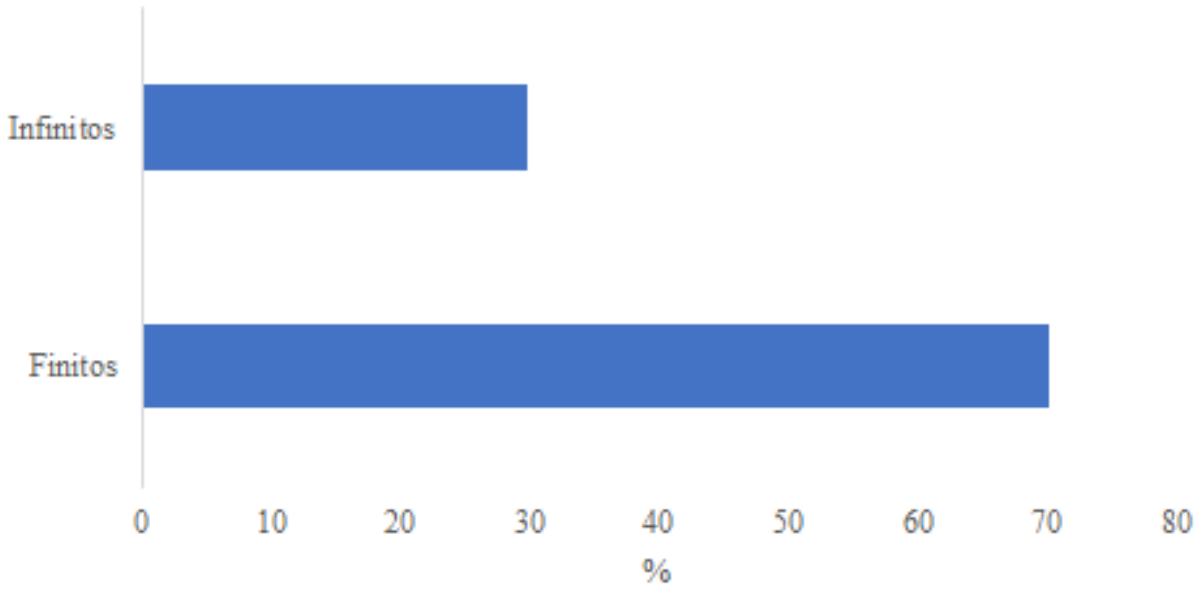

Fonte: Autores (2021). 
A partir dos dados obtidos fica notório que a educação ambiental precisa ser valorizada em escala global, de forma que mais pessoas, empresas, indústrias e sociedade estejam cientes das ações que prejudicam e destroem a natureza. Assim, a educação ambiental é a base para a conscientização ambiental da população para o alcance do desenvolvimento sustentável.

\section{Conclusão}

A maioria das pessoas que participaram da pesquisa, tem uma percepção ambiental significativa, conhecendo sobre o meio ambiente, ficando evidente que já ouviram sobre o assunto, mas quando se perguntou sobre a pegada ecológica, notou-se uma deficiência sobre este tema. O estudo de caso apontou que mais de $60 \%$ das pessoas conhecem sobre a pegada ecológica e as pessoas conhecem o meio ambiente e tem interesse em assuntos relacionados ao tema, dentre as pessoas pesquisadas, a minoria não conhece a Pegada Ecológica.

Diante dos resultados da pesquisa, nota-se que algumas pessoas conhecem a Educação Ambiental, mas, só conhecer não basta, é preciso que haja ações que ajude o meio ambiente, preservando-o para essa e as próximas gerações. Logo, é preciso mudar o jeito de viver e não apenas esperar que os recursos naturais acabem, senão, mudar para que esses mesmos recursos permaneçam, desse modo, a Educação Ambiental é o caminho para despertar a conscientização ambiental. Sugere-se que a Educação Ambiental formal e não-formal seja intensificada uma vez que ela precisa vir da base, as escolas precisam ensinar mais sobre o tema para que todo o conhecimento aplicado e adquirido transpasse os muros da escola e seja uma forma de despertar as pessoas e que provoque nelas mudanças e ações positivas.

\section{Referências}

Agenda 2030. Objetivo 12: Consumo e produção sustentável. http://www.agenda2030.org.br/ods/12/.

Alves, I. B., \& Fontgalland, I. L. (2021). A importância da reciclagem nas indústrias têxteis: o caso da indústria Martex Fiber. E-Acadêmica, 2(3), e212357. https://doi.org/10.52076/eacad-v2i3.57

Araújo, E. C., Soares, E. S., Farias, F. L. B., Silva, É. J. A., Silva, M. J., Sobrinho, J. B. S., \& Barros, A. T. (2020) (2020). Percepção ambiental de estudantes do ensino fundamental de uma escola pública. Brazilian Journal of Development, 6(1), 530-538. https://doi.org/10.34117/bjdv6n1-0

Berté, E. A., (2019). Indicadores socioambientais: a pegada ecológica como ferramenta para educação ambiental na escola (Bachelor's thesis, Universidade Tecnológica Federal do Paraná).65p. https://repositorio.utfpr.edu.br/jspui/handle/1/11045

Cardoso, D. C. C., Rosini, D. N., Pessoa, N. M., Schutz, E. L. D. \& Becegato. V. A., (2021). A educação não formal no processo de formação dos indivíduos com práticas de educação ambiental e a reutilização do resíduo sólido de madeira palete em Lages- SC. IBEAS Instituto Brasileiro de Estudos Ambientais. Gramado/RS. ISSN 2674-5992. http://www.ibeas.org.br/conresol/4conresol.htm

Galli, A., Iha, K.; Pires, S.M., Mancini, M.S., Alves, A., Zokai, G., Lin, D., Murthy, A. \& WackernageL, M. (2020). Assessing the ecological footprint and biocapacity of Portuguesecities: critical results for environmental awareness and local management. ScienceDirect. Cities, 96(1). https://doi.org/10.1016/j.cities.2019.102442

IBGE. https://cidades.ibge.gov.br/brasil/pb/campina-grande/panorama.

IBGE -Instituto Brasileiro de Geografia e Estatística- (ano pesquisado 2010, 2017 e 2020). https://www.ibge.gov.br/cidades-e-estados/pb/campinagrande.html. Acesso 08/11/2021.

INPE, Instituto Nacional de Estudos e Pesquisas Educacionais Anisio Teixeira. Censo Escolar (2021). https://www.gov.br/inep/pt-br/areas-deatuacao/pesquisas-estatisticas-e-indicadores/censo-escolar/resultados.

Iazdi, O., \& Pedroso, F. (2020). A pegada ecológica e a manutenção do capital natural: limites para o crescimento econômico? REVIBEC-Revista Iberoamericana De Economía Ecológica, 32(1), 102-119. https://redibec.org/ojs/index.php/revibec/article/view/vol32-1-5

Pereira, A. S., Shitsuka, D. M., Parreira, F. J. \& Shitsuka, R. (2018). metodologia da pesquisa cientifica. E-book. https://repositorio.ufsm.br/handle/1/ 15824 ? show $=$ full

PNUD Brasil. Objetivo 12: Consumo e produção sustentável. https://www.br.undp.org/content/brazil/pt/home/sustainable-development-goals/goal-12responsible-consumption-and-production.html

Rees, W. E. (1992). Ecological footprints and appropriated carrying capacity: what urban economics leaves out. Environment and Urbanization. 4(2). https://doi.org/10.1177/095624789200400212 
Research, Society and Development, v. 10, n. 15, e546101523145, 2021

(CC BY 4.0) | ISSN 2525-3409 | DOI: http://dx.doi.org/10.33448/rsd-v10i15.23145

Rodrigues, S. C. M., Dias, L. A. L., Carvalho, A. C., Fenzl, N. \& Lopes, L. O. C. (2019). Os recursos naturais no processo de desenvolvimento econômico capitalista. Uma breve reflexão. SEMIOSES: Inovação, Desenvolvimento e Sustentabilidade | Rio de Janeiro | ISSN 1981-996X. 13(4) out./dez. 2019. https://doi.org/10.15202/1981996x.2019v13n4p50

Santos, S. P. \& Gardolinski, M.T.H.A. (2016). A importância da Educação Ambiental nas escolas para a construção de uma sociedade sustentável. http://www2.al.rs.gov.br/biblioteca/LinkClick.aspx?fileticket=1VmNggPU170\%3D\&tabid=5639

Santos, K. A. S. A \&. Silva, R. C. (2021). Educação ambiental em espaços não formais: relato de experiências no parque das aves (Fóz de Iguaçu), PR, Brasil). Revbea, São Paulo. 16(2), 153-62. https://periodicos.unifesp.br/index.php/revbea/article/view/10566/8389.

Santos, K. A. S. A \&. Silva, R. C. (2021). O uso da Pegada Ecológica como metodologia para Educação Ambiental. Revista Brasileira De Educação Ambiental (RevBEA), 16(4), 516-535. https://doi.org/10.34024/revbea.2021.v16.11135

Severino, A. J. (2017). Metodologia do trabalho Cientifico. Cortez, 306.

Silva, J.B. (2021) Avaliação dos impactos dos índices de controle urbanístico: um estudo de cenários urbanos do bairro Vila Cabral. Dissertação (Mestrado). Programa de Pós-graduação em Arquitetura e Urbanismo da Universidade Federal da Paraíba, 94p. https://repositorio.ufpb.br/jspui/handle/123456789/21316

Souza, F. R. S. (2020) Educação Ambiental e Sustentabilidade: uma intervenção emergente na escola. Revista Brasileira de Educação Ambiental. Revbea, São Paulo, 15(3):115-121. https://doi.org/10.34024/revbea.2020.v15.9616

Schwambach, A. (2013) Avaliação da Pegada Ecológica de alunos do terceiro ano e oitava série das escolas estaduais do município de São Leopoldo/RS. IX encontro nacional de pesquisa em educação em ciências. Atas. INPEC Águas de Lindóia, São Paulo. 555-1. http://abrapecnet.org.br/atas_enpec/ixenpec/atas/indicepalchave.htm

Viana, E. C., Júnior, G. M. O., Cecílio, E. C. L. M. N., Sobral, S. E. C., \& Lima, O. M. L. (2019). A Educação Ambiental nos anos Iniciais do Ensino Fundamental/Environmental Education in the Early Years of Elementary Education. ID on line Revista De Psicologia, 13(44), 620-634. https://doi.org/10.14295/idonline.v13i44.1646

WWF. Pegada Ecológica. https://www.wwf.org.br/natureza_brasileira/especiais/pegada_ecologica/historico/> Visitado 10/2021. 